\title{
Prólogo
}

\section{Schopenhauer é um verdadeiro discípulo de Kant?}

\author{
Is Schopenhauer a true disciple of Kant?
}

\author{
Maria Lúcia Cacciola*
}

Universidade de São Paulo, São Paulo, SP, Brasil

\section{Resumo}

A pergunta que orienta esta reflexão nos conduz ao cerne da postura crítica de Schopenhauer em relação a Kant. Se, por um lado, o filósofo de Frankfurt nos oferece uma interpretação peculiar que parece se afastar do pensamento kantiano, por outro, parece ter como intenção apenas retificar os erros que considera estarem contidos nessa filosofia que, para Schopenhauer, não esclarece devidamente a relação entre intuição e conceito. A estrutura do pensamento kantiano, a sua arquitetônica, é rejeitada por Schopenhauer como um retorno ao racionalismo escolástico, que se mostra na supremacia da ordenação lógica do pensamento em relação à efetividade. Isso se reflete no que Schopenhauer denomina "o amor à simetria" de Kant, que o faz montar a sua tábua de categorias simétricas, esquecendo-se da autonomia do objeto da intuição, a ser garantida, segundo o filósofo de Frankfurt, pelo papel que o entendimento exerce na intuição imediata dos objetos.

Palavras-chave: Intuição. Entendimento. Reflexão. Pensamento. Categorias.

* MLC: Doutora, e-mail: mcacciola@uol.com.br 


\section{Abstract}

The question that guides this reflection leads us to the core of Schopenhauer's critical stance toward Kant. If, on the one hand, the philosopher of Frankfurt offers us a peculiar interpretation that seems to move away from Kantian thought, on the other hand, it seems only to rectify the errors which he considers to be contained in this philosophy which, for Schopenhauer, does not adequately explain the relation between intuition and concept. The structure of Kantian thought, its architecture, is rejected by Schopenhauer as a return to scholastic rationalism, which shows itself in the supremacy of the logical ordering of thought in relation to effectiveness. This is reflected in what Schopenhauer calls Kant's "love of symmetry," which causes him to mount his board of symmetrical categories, forgetting the autonomy of the object of intuition, to be guaranteed, according to the Frankfurt philosopher, by the role that the understanding exerts in the immediate intuition of the objects.

Keywords: Intuition. Understanding. Reflection. Thought. Categories.

Essa questão nos leva ao cerne do projeto crítico e a seu desenvolvimento nas filosofias depois de Kant, a saber, no chamado idealismo alemão.

Schopenhauer se declara o verdadeiro discípulo de Kant, segundo ele, nos cem anos que sucederam a filosofia kantiana, nada de significativo teria acontecido, a não ser sua filosofia. Os demais pós-kantianos teriam apenas, ao modificar o projeto crítico, visto com lentes de aumento os erros de Kant. Assim, Schopenhauer apesar de reconhecer a genialidade de Kant, se propõe a corrigir sua rota, nos pontos em que ela teria conduzido seus seguidores a uma leitura equivocada de Kant. Estes teriam reconduzido a filosofia para o terreno do dogmatismo, alvo do próprio projeto crítico.

O fio condutor da crítica de Schopenhauer é a dedução das categorias a partir dos juízos na Lógica Transcendental. A sua objeção à dedução liga-se as críticas ao predomínio do abstrato sobre o intuitivo, ao caráter sistemático da filosofia de Kant, e à concepção racional da moral kantiana.

No Mundo como vontade e representação, o filósofo admite uma visão do mundo dúplice, por um lado centrada num sujeito do conhecimento e por outro num ímpeto cego, a vontade. Nessa duplicação de sentido das 
coisas em geral, Schopenhauer segue a distinção kantiana entre fenômeno e coisa-em-si, deslocando, no entanto, o feitio desses conceitos. A essa duplicidade de pontos de vista sobre o mundo, corresponde uma duplicidade no indivíduo que é, ao mesmo tempo, sujeito do conhecimento e também corpo; este é condição do filosofar, já que o filósofo não é uma "cabeça de anjo alada" (SCHOPENHAUER, W1, p. 118). A vontade como querer-viver se manifesta no corpo como sua objetividade imediata, ou seja, a corporeidade não pode ser totalmente explicada num registro intelectual ou representativo, exigindo esse outro ponto de vista que dê conta da sua realidade de organismo. No capítulo I de O Mundo, Schopenhauer, depois de adotar a visão idealista, em que o mundo é representação de um sujeito que conhece, e afirmar a polaridade sujeito e objeto como o primeiro dado do conhecer, recusa esse único ponto de vista em nome da repulsa que se tem em admitir que o mundo seja mera ilusão, mera "criação" do sujeito cognoscente (SCHOPENHAUER, W1, p. 5). Tal idealidade do mundo viria suprimir inapelavelmente qualquer sentido moral, e a sua ausência seria para ele "a pior perversidade do espírito" (SCHOPENHAUER, V, p. 109). A vontade como querer viver deixa em aberto um outro tipo de conhecimento, capaz de suprimir a falta de sentido.

Sabemos que, para Kant, a duplicação do sentido das coisas em geral em objetos da experiência ou fenômenos e as coisa-em-si mesmas, leva à possibilidade de abrir um espaço para se pensar o Incondicionado, um lugar que, embora vazio, pudesse ser preenchido por determinações no campo prático ou moral. A exigência do sentido moral das ações humanas é, pois, satisfeita em Kant, pois a liberdade, como pressuposto necessário para a moral, pode então ser admitida sem empecilhos, se resguardando a sua eficácia. Ora, Schopenhauer como pertencente ao que se convencionou chamar de pós-kantismo, conserva em sua filosofia a mesma vertente, ou seja, a da preeminência da moral em relação ao conhecimento teórico, quando admite esse outro ponto de vista, o do mundo como vontade.

Apesar disso, o projeto kantiano vai sofrer profundas alterações, mesmo mantendo-se uma das linhas mestras do Criticismo que é a distinção entre fenômeno e coisa em si. As objeções a Kant ganham em clareza se considerarmos as preocupações fundamentais que as movem. A mais 
importante é expulsar qualquer resquício dogmático da filosofia de Kant, resto esse que Schopenhauer detecta na inferência da coisa-em-si como causa, e na admissão por Kant de uma razão prática ao lado de uma teórica e, acima de tudo, nos postulados de Deus, imortalidade da alma e liberdade, exigidos pelo Soberano Bem, união entre virtude e felicidade, o ponto culminante da Crítica da razão prática. Schopenhauer, como diz Nietzsche, professa um "decidido ateísmo filosófico" ao banir da filosofia tudo que evoque pressupostos teológicos; a filosofia deve, de uma vez por todas, liberar-se do jugo da teologia. Assim, sua metafísica imanente que vê no querer viver a essência do existente, baseia-se na recusa de qualquer transcendência, quer se manifeste num Absoluto ou numa inteligência ordenadora, ou mesmo numa vontade que, em última análise, se guie por ela. A vontade para Schopenhauer é cega, sem fundamento e sem finalidade, diferenciando-se do fenômeno.

Quais os pontos que merecem ser examinados para evitar a recaída no dogmatismo e perigo contra o qual Schopenhauer adverte?

1) O espírito sistemático;

2) O privilégio da abstração em face da intuição;

3) A admissão no campo moral de uma razão prática que teria atribuições paralelas à razão teórica.

\section{Crítica ao espírito sistemático}

Schopenhauer vai apontar em Kant o "amor pela simetria" (SCHOPENHAUER, 1980, p. 176) que o teria levado a adotar o espírito sistemático, responsável pelo retorno a metafísica clássica e ao dogmatismo que lhe é próprio. Ou seja, responsável pelo abalo do projeto crítico e pelo seu fracasso nas filosofias de Fichte, Schelling e Hegel.

A busca de um sistema para a filosofia transcendental, que é o denominador comum aos sucessores de Kant, já estava presente em Kant embora de modo ainda não completamente evidente.

O sistema kantiano, suas divisões e subdivisões, enfim o gosto pela simetria vai fornecer a estrutura da crítica de Schopenhauer à teoria do juízo de Kant. O filósofo de Dantzig mostra a ausência de "simplicidade, 
singeleza (naivität), ingenuité, candeur" (SCHOPENHAUER, 1980, p. 97) em Kant, afirmando que sua filosofia não evoca a grandeza e harmonia de proporções da arquitetura grega, mas lembra a arquitetura gótica. “Pois uma peculiaridade bem individual do espírito de Kant é o gosto singular pela simetria, que ama a multiplicidade variegada para ordená-la e para repetir a ordenação, em subordinações e assim por diante, como nas igrejas góticas" (Ibidem). No livro de Panofsky, Arquitetura gótica e escolástica, expõe as relações entre as manifestações culturais da arquitetura e da filosofia. É o mesmo espírito do tempo que traz à luz as expressões na cultura promovendo suas analogias. Para Panofsky, "a arquitetura gótica era a tradução em pedra da filosofia escolástica dos séculos XII e XIII". Schopenhauer, por sua vez, havia comparado a estrutura de pensamento do Aufklärer Kant com a arquitetura e jardins góticos; o que ele denomina "peculiaridade do espírito de Kant" (PANOFSKY, 1991, p. 31) é o seu extremado racionalismo e seu método dogmático herdado de Wolff, que o levam a retomar procedimentos escolásticos. O estilo gótico estaria presente não apenas na Escolástica, mas no "racionalismo" sistemático, reino da abstração. Mas o que interessa a Schopenhauer acima de tudo é denunciar, em todo predomínio de uma racionalidade abstraente, o resquício dogmático que se prende aos tempos áureos da escolástica, em que a filosofia como ancila (serva) da teologia refletia os dogmas religiosos. O sistema racional dedutivo que provém de princípios, afastando-se da vida e do devir, cristalizando-os em conceitos para aprendê-los, remete por fim à criação inteligente da Providência, a um Deus dotado de "esprit de géometrie": se no mundo nada é sabiamente ordenado, mas deixado a um ímpeto cego (blinder Drang), a Providência perde seu lugar.

Na análise de Panofsky a arquitetura gótica reflete o caráter sistemático dos tratados filosóficos, cuja estrutura - de acordo com um esquema, dividindo-se em seções, apresentadas em índice, com suas subdivisões por números e letras da mesma família hoje tão familiar - era desconhecida antes da Escola; ordem essa que data do século XIII. A Suma teológica de Santo Tomás é exemplo disso. Ao estabelecer a inspiração do pensamento escolástico no domínio das artes, elege a catedral do apogeu gótico, "como a summa do apogeu escolástico", segundo ele, 
“a catedral do apogeu gótico aspirava em primeiro lugar à completude, caminhando por meio da síntese e da eliminação em direção a uma solução completa e definitiva" (Ibidem). Outra exigência da escolástica em relação aos textos é a "estruturação segundo um sistema de partes e partes das partes homólogas" que desemboca numa hierarquia de níveis lógicos do tratado escolástico. "Se dividirmos toda edificação em três partes principais, a saber, o conjunto longitudinal, que consta de três naves, o transepto e o coro, descobrem-se as relações analógicas entre todas as partes da construção" (Ibidem). E essa pertinência de uma parte construtiva à outra leva ao princípio de dedutibilidade recíproca das formas dadas aos elementos - por exemplo, a exigência de inferir o interior do exterior e a forma das naves laterais da nave central - que Panofsky distingue das relações dimensionais da arquitetura românica. Assim, o racionalismo imperante na escolástica tem sua contrapartida na sua forma construtiva mais bem-sucedida: a catedral gótica.

A estrutura do pensamento kantiano, a sua arquitetônica, é, pois, rejeitada por Schopenhauer como um retorno ao racionalismo escolástico, que se mostra na supremacia da ordenação lógica do pensamento em relação à efetividade. Isso se reflete no que Schopenhauer denomina "o amor à simetria" de Kant, que o faz montar a sua tábua de categorias simétricas, esquecendo-se da autonomia do objeto da intuição, a ser garantida, segundo o filósofo de Frankfurt, pelo papel que o entendimento exerce na intuição. A saber, a referência intuitiva não é dada apenas pela sensação "surda e vegetal" que não chega a constituir qualquer representação, mas pelo intelecto que representa; o dado da sensação, à diferença de Kant, não representa, não se refere a nada, mas para tornar-se representação terá que, como efeito, ter de ser referido à sua causa por meio do intelecto, que opera através da lei da causalidade, que é justamente expressão de uma das modalidades do princípio de razão, a que rege o devir.

\section{Crítica à predominância do abstrato sobre o intuitivo}

Schopenhauer vai caracterizar seu método por oposição ao de Kant, como tendo como ponto de partida o conhecimento imediato e 
intuitivo, fonte de toda evidência e ponto de apoio necessário para o pensamento abstrato. Se o entendimento é a faculdade de intuir, a razão corresponde aos conceitos, às representações abstratas. $\mathrm{O}$ maior erro de Kant é, para ele,

a monstruosa afirmação de que sem pensamento, portanto sem conceitos abstratos, não se daria nenhum conhecimento de um objeto e que a intuição, porque não é um pensamento, também não seria um conhecimento e, simplesmente nada, a não ser uma mera afecção da sensibilidade, mera sensação! Ainda mais, que a intuição sem conceito seria completamente vazia e os conceitos sem intuição, seriam sempre algo ainda. Ora, isto é exatamente o contrário da verdade: pois são justamente os conceitos que adquirem todo significado, todo conteúdo, unicamente por sua referência às representações intuitivas, dos quais foram abstraídos, extraídos, quer dizer formados por abstração. As intuições ao contrário tem significado imediato e bastante grande (nelas objetiva-se a coisaemsi): elas representam-se a si mesmas, enunciam-se por si mesmas, não tem um conteúdo meramente emprestado como os conceitos (SCHOPENHAUER, W I, p. 562).

Os conceitos originam-se meramente na razão. Portanto a linguagem é sábia ao designar tal faculdade por reflexão, "pois ela é de fato um reflexo, uma derivação do conhecimento intuitivo" (Ibidem). Sem o conteúdo e o significado dados pelo intuitivo, o conhecimento abstrato é "vazio e nulo" (Ibidem). Ao contrário, para Kant, o espetáculo que o mundo intuitivo oferece compara-se a um teatro de marionetes, controlado pelo conhecimento abstrato.

Apesar dessa crítica, Schopenhauer admite a independência formal do conhecimento abstrato em relação ao intuitivo. Não estaria aí uma incoerência do filósofo? Esta impressão dissolve-se ao localizarmos a divergência na aplicação da forma do pensar para a determinação dos objetos da experiência. A filosofia kantiana exige que para tal determinação se apliquem conceitos puros do entendimento às intuições. Para Schopenhauer, ao contrário, a intuição empírica já é diretamente objetiva e, quando nos movemos no pensar, já abandonamos as coisas individuais e nos encontramos no domínio puramente conceitual. O pensamento apenas abstrai os dados comuns dos objetos, originando com isso conceitos 
universais. As representações abstratas não têm por função conferir realidade às intuições, mas servem apenas para "fixar seus resultados e tê-los a mão" (SCHOPENHAUER, WI, p. 537). A faculdade de abstração não é, pois, o entendimento, mas a razão, responsável pela elaboração da linguagem, permitindo a comunicação entre os homens. A palavra é assim o signo sensível do conceito e o meio para fixá-lo. Schopenhauer não deixa de referir a etimologia da palavra Vernunft, que provém do verbo vernehmen e que significa compreender pensamentos comunicados por meio de palavras (SCHOPENHAUER, WI 525, III p. 618). É a economia da Razão que permite ao homem pensar o essencial, deixando de lado as diferenças acessórias e ultrapassar o momento presente, podendo assim olhar retrospectivamente o passado e projetar o futuro. É ela que torna possível uma memória, que fixa o fluxo contínuo do acontecer no mundo da experiência.

Se Kant isola os conceitos abstratos de seu conteúdo para, de acordo com o método das ciências, chegar ao intuitivo, ordenando-o e tomando posse dele, ele não se questiona sobre o que acontece com o mundo intuitivo quando este recebe as formas do pensamento abstrato. Schopenhauer compara o processo de abstração à metabolização dos elementos pelo organismo, que dá origem a composições em que não mais se reconhece a constituição originária do que foi ingerido. Ao receber uma forma lógica, o mundo fenomênico perde uma série de diferenças, adquirindo outras próprias à forma de pensar, o que torna impossível o regresso do abstrato ao intuitivo.

Se os conceitos abstratos têm, em Schopenhauer, uma esfera própria, em nada contribuindo para o conhecimento intuitivo, os juízos lógicos não podem ser a matriz das categorias, enquanto essas, para Kant, são as condições de todo o conhecimento.

Kant teria sido seduzido por seu "amor à simetria arquitetônica" ao tomar como fio condutor seu grande achado de que tempo e espaço são formas a priori da sensibilidade e intuições puras subjacentes à empírica e, a partir daí, ter acreditado que os conceitos adquiridos empiricamente teriam como seu pressuposto certos conceitos puros, ou seja, que o pensamento empírico efetivo só seria possível através do pensamento puro, o qual em si mesmo não teria qualquer objeto, mas que teria de 
tirá-los na intuição. A estética transcendental adquiriu simetricamente um correlato numa lógica transcendental. E aqui ele argumenta relembrando a asserção de que a refutação de um erro só se dá completamente quando se descobre sua gênese psicológica; ele acredita tê-lo feito ao mostrar que foi a descoberta dos a prioris de espaço e do tempo para nossas intuições empíricas, que teriam levado Kant a buscar outros a prioris no entendimento por analogia, levado pelo seu "amor à simetria".

Ora, Schopenhauer trata então de explicar a origem da tábua dos juízos, mostrando a origem de seus momentos e o caráter infundado da dedução das categorias a partir deles. A sua concepção funda-se em que o conhecimento reflexivo ou a razão tem apenas uma forma capital e que esta é o conceito abstrato. Os juízos são unificação de conceitos com formas determinadas, que decorrem da razão. Schopenhauer percorre as formas de juízo e a tábua das categorias exibindo o caráter forçado da dedução, que afinal se assenta sobre pés de barro, estando baseada tão só no amor pela simetria. E é esta tábua das categorias que, segundo o parágrafo 39 dos Prolegômenos, deve ser o fio condutor pelo qual toda metafísica e toda consideração científica se ordena. Esse fundamento e o modo pelo qual realiza a simetria arquitetônica por toda parte da filosofia de Kant; torna-se o leito de Procusto no qual Kant entala todas suas considerações. Schopenhauer se esforça por mostrar que não há uma relação comprovada entre os tipos de juízo e as coisas que lhes são subsumidas, tanto físicas como morais, destacando o caráter arbitrário das designações kantianas (SCHOPENHAUER, WI, p. 541).

Concluindo, para Schopenhauer desaparecem os juízos de experiência que exigem a aplicação das categorias, restando apenas juízos de percepção.

\section{Crítica à razão prática}

A crítica à moral kantiana como moral racional reflete a crítica do predomínio do abstrato sobre o intuitivo. Assim, o fato de Kant ter distinguido entre uma razão teórica e uma razão prática é o objeto de censura, pois esta última retoma a noção de anima rationalis, indestrutível, em contraposição à anima sensitiva e à anima vegetativa, classificação essa de 
origem escolástica. Assim, apesar de Kant ter posto um fim às hipóstases transcendentes, expressa detalhadamente na Crítica da razão pura, na Moral, e principalmente na Crítica da razão prática domina o pensamento de que "a essência do homem consiste na razão" e não na vontade, único núcleo metafísico no homem para Schopenhauer.

Lecce, 30 maggio 2012.

\section{Referências}

KANT, I. Crítica da razão pura. Trad. Manuela Pinto dos Santos e Alexandre Fradique Morujão. Lisboa: Fundação Calouste Gulbenkian, 1997.

PANOFSKY, E. Arquitetura gótica e escolástica. São Paulo: Martins Fontes, 1991.

SCHOPENHAUER, A. Sämtliche Werke (Hrsg. Paul Deussen), Bd. 13. München, 1926.

SCHOPENHAUER, A. Crítica da filosofia kantiana. Trad. Maria Lúcia Cacciola. São Paulo: Abril Cultural, 1980. (Coleção Os Pensadores, Vol. Schopenhauer).

Recebido: $14 / 02 / 2018$

Received: 02/14/2018

Aprovado: 28/02/2018

Approved: 02/28/2018 